$\mathcal{G}_{\text {http://dx.doi.org/10.3765/sp.6.10 }}^{\text {Semantics \& Pragmatics Volume 6, Article 10: 1-43, } 2013}$

\title{
Experimenting with the king of France: Topics, verifiability and definite descriptions*
}

\author{
Márta Abrusán \\ University of Oxford / Lichtenberg \\ Kolleg / CNRS, IRIT
}

\author{
Kriszta Szendrői \\ University College London
}

Submitted 2012-07-14 / First decision 2012-10-02 / Revision received 2013-02-01 /

Accepted 2013-03-17 / Final version received 2013-05-13 / Published 2013-10-01

\begin{abstract}
Definite descriptions with reference failure have been argued to give rise to different truth-value intuitions depending on the local linguistic context in which they appear. We conducted an experiment to investigate these alleged differences, thereby contributing new data to the debate. We have found that pragmatic strategies dependent on verification and topicalisation, suggested in the context of trivalent/partial theories, indeed play a role in people's subjective judgments. We discuss the consequences of these findings for all major approaches to definite descriptions (i.e. Russellian, Strawsonian, pragmatic). Finally, we offer a discussion of the relative contribution of verificational and topicality effects on truth values, reaching the conclusion that verification is primarily relevant and topicality is dependent on that. We thus support von Fintel's (2004) position on the primacy of verification, but not his dismissal of topicality as a factor.
\end{abstract}

Keywords: definite descriptions, presupposition, experimental pragmatics, verifiability, topics

* Thanks to György Abrusán for his invaluable help with statistics and Mike Coleman for programming. We are grateful to the editors and three anonymous reviewers for their extremely valuable suggestions, as well as Nathan Klinedinst and Daniel Rothschild for insightful comments on an earlier draft; Klaus Abels, Bob Borsley, Judit Gervain, Vanessa Harrar, Ad Neeleman and the audiences at UCL, University of Oxford, Essex University, The 18th Amsterdam Colloquium and The 35th GLOW Colloquium for their helpful questions and suggestions. The first author acknowledges financial support by the Mellon Foundation and the Lichtenberg Kolleg, Georg-August-Universität Göttingen. We would also like to thank Somerville College in Oxford for providing us with inspiring space, food and coffee that helped the ideas in this paper spring to life, and those members of the College who came to take the test for free.

(C)2013 Márta Abrusán and Kriszta Szendrói

This is an open-access article distributed under the terms of a Creative Commons NonCommercial License (creativecommons.org/licenses/by-nc/3.o). 
Márta Abrusán and Kriszta Szendrői

\section{Introduction}

According to Russell (1905, 1957), sentences with definite descriptions entail the existence of a unique individual that satisfies the description. When such an individual does not exist, as in (1), the sentence is false. Famously, Strawson (1950, 1964) argued that Russell's theory cannot predict why speakers (like him) feel "squeamish" about assigning the truth-value 'false' to sentences such as (1). His proposal (which can be traced back to Frege 1892) was that definite descriptions instead of asserting, presuppose the existence of a unique individual that satisfies the description: when this presupposition is not met, the question of truth or falsity does not even arise and so the sentence does not have a truth-value. A third possibility (cf. Stalnaker 1974, 1978) is that sentences with definite descriptions entail the existence of a unique individual satisfying the description and in addition also require that the existence of a unique referent be presupposed.

(1) The king of France is bald.

Strawson (1964) has noted however that truth-value intuitions change when the same definite description appears in different contexts. He conceded that according to his intuition, examples such as (2) do appear to be straightforwardly false. This in turn requires some explanation from the approach according to which (2) should not have a truth-value.

(2) The exhibition was visited yesterday by the king of France.

Since Strawson's observation, various factors have been identified in the literature that might influence our truth-value intuitions about sentences with reference failure noun phrases. Strawson (1964) himself (cf. also Reinhart 1981 and many others) have identified topic-comment structure as a factor. Others (cf. Fodor 1979, Lasersohn 1993, von Fintel 2004) stressed the importance of background knowledge based on which the sentence could be verified (or not), independently of the existence of the problematic referent. Sometimes, conflicting judgments have been asserted, which makes it hard to evaluate the relative import of the theories.

Our main aim in this paper was to investigate the truth value intuitions reported in the literature in an experimental setting. With this in mind, we have conducted a behavioural experiment that was designed to capture people's intuitions about sentences like (1)-(2). We have found that truth-value intuitions indeed depend on the nature and the structure of the sentence in which 
definite descriptions occur. In particular, we found that both the sentence's topic-comment structure (as suggested by Strawson 1964 and Reinhart 1981) and the sentence's verifiability (as suggested by Lasersohn 1993, von Fintel 2004) are important factors that influence truth-value intuitions in certain utterances. However, interestingly, the predicted differences did not seem to affect truth-value judgments in positive sentences, only negative ones. We offer a discussion of this difference in section 5.2. We note also that although the idea that people's truth-value intuitions might be shifting according to sentential context was originally proposed by truth-value gap theories, it is possible to reconcile our results with all the three major theories of definite descriptions, provided they incorporate pragmatic mechanisms for arriving at a truth-value intuition. (We note however that maintaining the Russellian and the Strawsonian position requires certain non-trivial stipulations, while the pragmatic account can explain our data rather straightforwardly.) Our results thus support the idea in Lasersohn 1993 and von Fintel 2004 according to which it is useful to differentiate the actual semantic truth value from the intuitive truth-value felt by speakers. We note further that keeping in mind this difference is informative when assessing other theories of definite descriptions as well. In the final part of the paper we take a closer look at the different factors identified by the three proposals: verifiability (von Fintel 2004, Lasersohn 1993) and topicality (Strawson 1964 and Reinhart 1981) and offer a way to reconcile these seemingly divergent factors. Our conclusion is that verification is the crucial factor, and topicality is parasitic on that.

\section{Possible (pragmatic) factors behind wavering truth-value judgments}

Strawson (1964) has proposed that one factor behind the difference in (1) and (2) is the topic-comment structure of the sentence. ${ }^{1}$ Topics are understood to be the constituents that the sentence is pragmatically about. Strawson proposed that when the definite description is not topical, it is "absorbed" into the meaning of the predicate, and since it is not a referring expression anymore, its presupposition is turned into an existential statement. This predicts the difference between (1) and (2): The noun phrase the king of France is topical in (1) hence in a context where it is known that France has no king, it leads to a presupposition failure, associated with "squeamishness".

1 Strawson sometimes talks about 'subject' instead of topic, but the discussion makes it clear that what he meant was more like the notion of topic in contemporary linguistic theory. 
In (2) the same noun phrase is not topical (the topic being the exhibition), instead it is absorbed into the predicate, and so the sentence is simply false.

Another set of examples where the topic-based approach might be relevant are cleft and focus constructions, and answers to questions (cf. Strawson 1964, Atlas 2004, Schoubye 2009). The example (1) is said to be false in the context (3a), as is its cleft version in (3b):

(3) a. A: What other examples are there of famous contemporary figures who are bald?

B: The king of France is bald.

b. It is the king of France who is bald.

Strawson suggests that what is the topic in these cases is the set of bald celebrities, made salient by the question. (A similar explanation can be given to examples with focus or cleft-constructions). ${ }^{2}$

The topic approach has been adopted and developed further by many researchers, most importantly by Reinhart $(1981,2006)$. (See also Hajičová 1984, Gundel 1977, Lambrecht 1994, Erteschik-Shir 1997, Atlas 2004, Geurts 2007, Schoubye 2009, among others.) Many of these approaches only keep the idea of the relevance of topichood in some form, but do not necessarily adhere to Strawson's original idea of "absorption". Sometimes the original idea has been simplified to effectively stating that definite descriptions trigger a presupposition only when topical, and otherwise they do not.

However, von Fintel (2004) dismissed the relevance of topichood. He claimed that topichood and existential presuppositions have nothing to do with each other:

"This idea about the link between topichood and existential presupposition continues to be a very popular assumption and can for example be found in: Reinhart (1981, 2006); Hajičová (1984); Gundel (1977); L. R. Horn (1986); Lambrecht (1994); Erteschik-Shir (1997); Zubizarreta (1998). Concrete and explicit formalizations of this idea are hard to find, but see work by Cresti (1995) and Percus (1997, 1998).

Let me be blunt: these analyses are fundamentally mistaken." (p.277)

2 The same idea can also be recast in verificational terms, as suggested by von Fintel (2004), except instead of topic, the list of bald celebrities is now the contextually salient entity that can serve as a foothold for verification. 
Experimenting with the king of France

One reason to doubt the relevance of topichood, von Fintel (2004) argues, is that in some cases even definite descriptions that are uncontroversially topics do not seem to trigger the "squeamishness" associated with presupposition failure, cf. (4):

(4) Let me tell you about my friend, the king of France. I had breakfast with him this morning.

According to classic tests for topichood (cf. Reinhart 1981) an expression such as Let me tell you about $a$ indicates that $a$ is a topic. Thus the pronoun in the second sentence referring to the topic noun phrase the king of France should give rise to "squeamishness", contrary to fact. ${ }^{3}$

Another reason to question the idea that the existential presupposition is absorbed into the predicate (or is just non-existent) when the definite description is not a topic is that the existential presupposition of definites seems to project out of embedded contexts, such as the antecedents of conditionals, whether or not the definite is topical. Thus (5) still seems to imply the existence of a French king, which suggests that the definite is still presuppositional, despite not being the topic.

(5) If the king of France is wise, James (the Francophobe) will be quite disappointed. (von Fintel 2004: 271)

This latter observation highlights a very important point, identified most clearly in this context by von Fintel. Namely, that our intuitions about accepting or rejecting a sentence as true or false, and the sentence's actual semantic truth-value (and hence its presuppositionality) are potentially two separate things. Speakers might feel that a sentence is false (or true) even when semantically it has no truth-value, as long as they can find some reason based on which they can reject (or accept) the sentence. The feeling of "squeamishness" arises only when all pragmatic repair strategies for dealing with a truth-valueless sentence fail.

The first proposal in this spirit was due to Lasersohn (1993). ${ }^{4}$ His main focus was on examples such as (6) which is said to be judged false. Lasersohn's observation was that in a situation where the chair in front of the

3 In fact, strictly speaking there is no definite description in the second sentence, only a co-referent pronoun, which may also affect the judgments.

4 See also Lappin and Reinhart 1988 for a verification based proposal about the existential presupposition of quantifiers such as all or none. 
speaker is empty, or when it is occupied by somebody other than the king of France, (the only two possibilities in our context), speakers have enough grounds to reject this sentence: They can look at the chair and see that the king of France (whether or not he exists) is not in it. This is enough reason to reject (6) as false. ${ }^{5}$

(6) The king of France is sitting in this chair.

"even if we suspend our knowledge that there is no king of France, there is no way of consistently extending our information to include the proposition that the king of France is sitting in the chair. Such an extension is impossible because we know the chair to be empty." (Lasersohn 1993: 116)

In contrast, in the case of (1), in the absence of background knowledge about the hairstyle of French royals, speakers do not have enough grounds to reject or accept the sentence, and are left with the feeling of squeamishness. Thus Lasersohn's theory rests on the following tenets (Here we partly make use of von Fintel's exegesis of Lasersohn's exposition):

a. Assume two kinds of truth-values: (i) semantically assigned values 1, o and a third value \#, which corresponds to 'neither o or 1' (ii) pragmatically assigned values TRUE, FALSE which represent the status of a sentence with respect to a given body of information, and correspond to acceptance and rejection. ${ }^{6}$

b. Once we are faced with presupposition failure (neither o nor 1), there are fall-back strategies to fill in the gap and arrive at TRUE and FALSE.

c. Lasersohn's fall-back strategy: Step 1: revise the given body of information to remove the knowledge that there is no king of France. Step 2: See if the given body of information can be consistently extended to include the target proposition.

5 Whether or not the king of France is the topic here is not easy to establish, because although it is in subject position, deictic demonstrative expressions are good candidates for topics as well.

6 Cf. "I do believe that an affirmative statement which might otherwise be judged of indeterminate truth value (because it contains a term which fails to refer) can instead be judged false, provided the context makes it possible to determine that the statement could not possibly be true regardless of whether the term has reference or not. Conversely, negative statements can be judged true in analogous circumstances." (Lasersohn 1993: 115) 
Experimenting with the king of France

A consequence of Lasersohn's analysis is that only those propositions are predicted to have the truth-values FALSE (or TRUE) that are in direct conflict (or in accordance) with what can be concluded from the given body of information.

This conclusion has been argued to be too weak by von Fintel (2004), based on examples such as (7), which he argues is felt to be FALSE, even in the absence of any information about who is on a state visit to Australia this week.

(7) The king of France is on a state visit to Australia this week.

He proposes to add another fall-back strategy, besides (c) above: ${ }^{7}$

d. Rejection/acceptance might (also) be based on the possibility of examining the intrinsic properties of a contextually salient independent entity (that everyone agrees exists).

This suggestion explains (7), even if the given body of information does not contain anything about who was visiting Australia. In principle, we could examine the properties of Australia and see whether the king of France is in it or not. Australia thus serves as a salient foothold for verification, based on which the truth of the sentence in (7) can be evaluated. ${ }^{8}$

Two final points are important to note. The first concerns independence: As von Fintel observes, "the mere presence of a referential item does not necessarily prevent \#-judgments. The sentence has to make an independently falsifiable claim about the entity referred to." (von Fintel 2004: 289).

7 That both (c) and (d) are needed is suggested by examples that fall under (c) but not (d): The king of France can jump 100 feet into the air unaided. (Example from Bezuidenhout \& Reimer 2004 discussing von Fintel 2004). However, if general laws can also be independent footholds for rejection/verification, then Lasersohn's account can be subsumed under von Fintel's, and thus (c) is a subcase of (d).

8 Note that there is a potential overlap for the theories discussed here. For instance, in an utterance where the object is the reference failure NP and the subject is an independent NP both von Fintel and Strawson/Reinhart would predict that a definitive truth-value can be arrived at, but for different reasons. For von Fintel, the presence of the independent NP is crucial and its position within the utterance irrelevant. For Strawson, under the assumption that subjects are easily construed as topics, this utterance would get a definitive truth-value judgment, in contrast with an utterance where the reference failure NP is the subject. Reinhart (1981) did not subscribe to this assumption. Rather, she assumed that any subject or object NP can be felicitously selected as a topic. It is thus only in syntactically marked topic constructions that the position of the other NP would make a clear difference in judgments. 
He claims that while (8a) seems simply false, (8b) leads to a judgment of "squeamishness". This difference follows assuming that the identities of people who die in a car accident would be listed under the properties of the accident, while the identities of people who heard about the accident would not be. Thus, in the latter case the sentence cannot be falsified on the basis of whether the car accident has the property of the king of France having heard about it.
a. The king of France died in the car accident on the turnpike last night.
b. The king of France has heard about the car accident on the turn- pike last night.

Second, the contextually salient entity that can serve as a foothold for verification does not have to be mentioned in the sentence (a list of bald people in the hand might do), and could even be an abstract entity such as the time point denoted by an indexical, as in the sentence The king of France is jogging right now.

Thus there are three factors that have been suggested to pragmatically influence truth-value judgments: topicality of the definite description (Strawson / Reinhart), the presence of an independent body of knowledge based on which the sentence can be actually verified (Lasersohn), and the presence of an independent entity based on which the sentence could be verified in principle (von Fintel). ${ }^{9}$ These factors have been proposed in the context of truth-value gap theories, mostly to defend these from criticisms pointing at cases where the felt intuitive truth-value was different from the one predicted by the (pure) Strawsonian approach. Nevertheless, such pragmatic strategies, if they exist, could in principle also interact with any semantics for definite descriptions, e.g. the Russellian and the Stalnakerian approach. Thus the existence of pragmatic strategies that people employ to arrive at a truth-value - if proven - is not in itself a support for the truth-value gap account. We will come back to this point in more detail when we discuss our results, in Section 5 .

9 An interesting proposal concerning factors that might influence truth-value judgments was also made in Yablo 2006. Our experiment did not specifically test the predictions of this theory. 
Experimenting with the king of France

\section{The experiment}

\subsection{Methodology}

Our aim was to investigate whether native speakers' judgments of sentences with reference failure NPs can illuminate the theoretical debate. The need for empirical data is especially pressing given that there are conflicting data reported in the literature. There is also a further specific reason to gather data in a controlled setting. We have seen above that some proposals highlight the potentially nondeterministic aspect of the judgment: the intuitive truthvalue of a sentence depends on whether or not a certain pragmatic fall-back strategy is followed. But the nature of such fall-back strategies remains not precisely worked out: Can they be violated? Is it possible that speakers follow different strategies, or that even the same speaker follows different strategies on different occasions? Such a situation seems particularly challenging for introspective analysis, and suggests that more data should be gathered.

We investigated how participants judge different types of sentences with reference failure noun phrases, such as the king of France. The experiment was advertised as a trivia quiz. Our critical items appeared alongside twice as many filler items that would present simple true or false statements about the world, which were determined to be accessible knowledge to our participants in a series of pilot studies e.g. Paul McCartney was a member of the Beatles. Our intention was that this design would allow us to present the utterances involving reference failure noun phrases of the 'king of France'-type in a fairly natural setting. We also assumed that the trivia quiz setting would ensure that participants consider our utterances in the context of their knowledge of the actual world and would not, for instance, consider fictional worlds.

We tested 33 native speakers of English (mostly British English, all of them familiar with basic elements of British culture), aged 20-55, most of whom participated for a small fee. Participants first read instructions given to them on the computer screen, reproduced in (9).

(9) In this experiment, statements will appear on your screen. If you think a statement is true, you should click on the 'TRUE' button. If you think a statement is false, you should click on the 'FALSE' button. Sometimes, it may happen that you cannot decide. In those cases, you should click on the 'CAN'T SAY' button. Please do not dwell on your decision for too long. There is no right or wrong answer! 
After a short practice session, after which they were given the opportunity to ask any questions, participants were left alone with a program which presented the test items one-by-one on the screen. Each item contained one sentence, as shown in (10). Participants could use the mouse to click on the buttons. After they chose an answer, the next item appeared automatically.

(10) Example of an experimental trial:

The king of France is bald.

FALSE CAN'T SAY TRUE

There were eleven test conditions, with eight test items in each condition. The test items were obtained by placing 8 definite descriptions that lack referents (listed in (11)) in eleven types of sentential contexts, (the test conditions), illustrated in Table 1. More on the test conditions below. (cf. also Appendix 1 for a full list of test items.)

(11) the king of France; the emperor of Canada; the Pope's wife; Princess Diana's daughter; the beaches of Birmingham; the Belgian rainforest; the coral reefs of Brighton; the volcanoes of Kent.

The 88 test items were supplemented by almost twice as many filler items. Altogether, there were 253 items presented in three blocks. The items were pseudo-randomised: there were no items from the same condition, or with the same NP, closer than 4 trials. The statements were presented in three separate blocks counter-balanced for order effects. The following are examples of filler items:

(12) Examples of filler items:

a. America was discovered by Christopher Columbus. (TRUE)

b. Paul McCartney was a member of The Beatles. (TRUE)

c. London was bombed during the Vietnam war. (FALSE)

d. The Queen doesn't wear a hat in public. (FALSE)

Our assumption was that if participants feel 'squeamish' about assigning a truth-value to a particular item, they would press the CAN'T SAY label. There are two methodological points we would like to address. First, how did we try to make sure that participants who felt 'squeamish' indeed pressed the CAN'T SAY label? In other words, how did we try to avoid so-called false 
Experimenting with the king of France

\begin{tabular}{|c|c|c|}
\hline No & Description & Example \\
\hline Co & $\begin{array}{l}\text { base line: ref. failure NP, } \\
\text { no extra NP }\end{array}$ & The king of France is bald. \\
\hline $\mathrm{C}_{1}$ & $\begin{array}{l}\text { control: no presupposi- } \\
\text { tion }\end{array}$ & France has a king and he is bald. \\
\hline $\mathrm{C}_{2}$ & $\begin{array}{l}\text { von Fintel: independent } \\
\text { unknown NP }\end{array}$ & $\begin{array}{l}\text { The king of France is on a state visit to Australia this } \\
\text { week. }\end{array}$ \\
\hline $\mathrm{C}_{3}$ & $\begin{array}{l}\text { Lasersohn: independent } \\
\text { known NP }\end{array}$ & The king of France is married to Carla Bruni. \\
\hline $\mathrm{C}_{4}$ & $\begin{array}{l}\text { S./ R.: reference failure NP } \\
\text { in topic }\end{array}$ & $\begin{array}{l}\text { The king of France, he was invited to have dinner } \\
\text { with Sarkozy. }\end{array}$ \\
\hline $\mathrm{C}_{5}$ & $\begin{array}{l}\text { Strawson/ Reinhart: other } \\
\text { NP in topic }\end{array}$ & $\begin{array}{l}\text { Sarkozy, he was invited to have dinner with the king } \\
\text { of France. }\end{array}$ \\
\hline C6 & negation of Co & The king of France isn't bald. \\
\hline $\mathrm{C}_{7}$ & negation of $\mathrm{C}_{2}$ & $\begin{array}{l}\text { The king of France is not on a state visit to Australia } \\
\text { this week. }\end{array}$ \\
\hline $\mathrm{C} 8$ & negation of $\mathrm{C}_{3}$ & The king of France is not married to Carla Bruni. \\
\hline C9 & negation of $\mathrm{C}_{4}$ & $\begin{array}{l}\text { The king of France, he wasn't invited to have dinner } \\
\text { with Sarkozy. }\end{array}$ \\
\hline $\mathrm{C} 10$ & negation of $\mathrm{C}_{5}$ & $\begin{array}{l}\text { Sarkozy, he wasn't invited to have dinner with the } \\
\text { king of France. }\end{array}$ \\
\hline
\end{tabular}

Table 1 Examples of test conditions, illustrated here with the king of France 
negatives? Second, how did we try to avoid so-called false positives, i.e. how did we ensure that those who press CAN'T SAY do so for the reason that they felt 'squeamish' about the item in question? This latter issue is more important. To use an analogy from tennis, it is important whether the ball is in or out, but only if it gets over the net first. If one does not get the ball over the net, it doesn't matter if it would have been in or out. So, avoiding false positives is crucial, while failing to completely eliminate false negatives would simply underestimate the effect. So, let us start with our second point. In a trivia quiz, people may assign the CAN'T SAY label to an item if they lack the knowledge necessary to make the judgment. This is why we included our control condition, $\mathrm{C}$. If anyone did not know whether France had a king or whether the Pope had a wife etc., they would assign a CAN'T SAY label not only to our test items, but also to our control items: France has a king and he is bald; The Pope has a wife and she is a lawyer, etc. Any participants who assigned CAN'T SAY labels to our control items would therefore be excluded. In addition, we also performed several rounds of pilot studies to ensure that participants felt comfortable judging our filler items, i.e. that our expectations about their knowledge of British culture were carefully adjusted to meet participants actual knowledge.

Let us move on to the subject of false negatives, i.e. the possibility that some of our participants would feel 'squeamish' about assigning a truthvalue to a particular item, yet they would not press the CAN'T SAY label. In pilot studies, we found that in a substantial amount of cases participants tended to assign FALSE label to many of our test conditions, at least in the positive conditions (Co- 5 ) (more on this discrepancy below). It is, of course, possible that this was due to the fact that, at least for some participants, the CAN'T SAY label does not adequately represent the kind of 'squeamishness' associated with experiencing a truth-value gap. Our pilot studies involved different labels, but we did not find a difference among them. We took the methodological decision to stop short of making the judgment concerning the lack of truth-values conscious for our participants by applying a label such as 'NEITHER TRUE NOR FALSE' or by training participants to judge sentences in Condition o as 'CAN'T SAY'. Our reason for this was twofold. First, the point of this experiment was to obtain unconscious judgments from native speakers. Making the judgments conscious by training our subjects would have gone counter to this aim. Also, we were worried that such a blunt approach may invite participants to scan sentences for reference failure noun phrases and simply apply the 'correct' CAN'T SAY-label to each of them 
Experimenting with the king of France

without actually judging the sentences. Finally, we were also worried that in case we were to get results that mesh with our predictions, we would be open to the criticism that we nudged our participants in the right direction.

Note, however, that we made sure that avoidance of the 'CAN'T SAY' label was not due to a general unwillingness on the part of our participants to admit their ignorance. In one of the pilot studies we tested fillers targeting the 'CAN'T SAY' response, such as (13). Participants readily chose this option suggesting that they did not feel pressurized to hide their ignorance by choosing a definite truth value. In the main experiment we decided to take these items out in order not to confuse the lexical meaning participants potentially associate with 'CAN'T SAY'.

(13) Croatia is part of the European Union.

Finally, although it is thus not clear what precise interpretation participants have in mind when they assign a 'CAN'T SAY' label, or even if they necessarily have a single interpretation in mind when they do, we think it is possible to adjudicate between the different theoretical proposals by mostly concentrating on the (relative) proportion of TRUE or FALSE responses in our critical conditions. Now we will explain the specific predictions of the various proposals with respect to our conditions.

\subsection{Predictions}

Condition o served as our base-line. It involved a reference failure NP, such as the king of France, in the subject position. There was no other NP in the predicate. All truth-value gap theories agreed that such sentences lead to 'squeamishness'. So, to the extent that our experiment is successful in tapping into this 'squeamishness', all three approaches surveyed (Strawson/ Reinhart; von Fintel, Lasersohn) would predict that participants will be inclined to press the 'CAN'T SAY' button when presented with these sentences.

In order to make sure that any CAN'T SAY-judgment on Condition o items is due to the participant being aware of the lack of referent for our definite descriptions and not due to the fact that the statement was beyond their knowledge base, we included a control condition, Condition 1. Here the existential presupposition associated with our NP was formulated as an assertion, e.g. France has a king and he is bald. This conjunction as a whole is not presuppositional. Therefore, we expected that anyone who knows that France does not have a king would judge this sentence as 'FALSE'. In 
contrast, if they did not know whether France has a king or not, they would press the 'CAN'T SAY' button, in which case they would be excluded from the experiment.

Condition 2 aimed to test von Fintel's theory. These items involved an independent NP alongside the referentially challenged NP. Von Fintel's prediction was that there would be a higher number of FALSE judgments in this condition than in Condition o. This is because the presence of an independent (referentially sound) NP would provide a foothold for verification of the truth-value of the statement.

Condition 3 aimed to test Lasersohn's theory. These items were individually paired with 8 filler items. For example, the matching filler item for (Table 1, C3) and (Table 1, C8) was (14). Each matching filler item involved a true statement. It was predicted that participants who judge such items TRUE would have the necessary knowledge to reject the corresponding test items in Condition 3 by inference. In this particular example, if someone knows that Sarkozy is married to Carla Bruni then they can safely reject the statement that says that the king of France is married to Carla Bruni by inference, and without having to confront the presupposition failure in the subject NP.

(14) Control item: Sarkozy is married to Carla Bruni.

So, Lasersohn predicted that there would be more FALSE judgments in Condition 3 than in Condition o and that this would be contingent on the number of TRUE judgments in the corresponding filler items.

Conditions 4 and 5 aimed to test the hypothesis, put forward by Strawson and Reinhart, that judgments are influenced by whether a referentially challenged NP is topical or not. Conditions 4 and 5 involve the same sentences, modulo their topic-comment structure, cf. (Table 1, C4) vs. (Table 1, C5). Strawson and Reinhart predicted that there should be more FALSE judgments in Condition 5, where a referentially sound NP was in the topic position, than in Condition 4, where the reference failure NP was topicalised. Our design setting did not allow for triggering topicality by appropriate discourse context, so we used left dislocation structures. These are taken to mark topichood by many in the literature (Gundel 1974, 1985; Halliday 1967; Reinhart 1981; Prince 1997). In fact, English left dislocation is given as an example of a 'prototypical topic-comment construction' by Gundel \& Fretheim (2004). ${ }^{10}$

10 In fact, this raises an important subtle point whose relevance was noted by an anonymous reviewer. Since our examples in Conditions 4 and 5 involve left dislocation, it is not entirely clear whether any effect we get is strictly speaking due to the topical status of such NPs or 
Experimenting with the king of France

In addition, we can compute the predictions of the various theories for the conditions that are not directly designed to test them. For instance, von Fintel predicted that the presence of an independent NP was enough to induce a rejection irrespective of the actual knowledge the speaker has about the properties of the NP and irrespective of the topicality of the NP in question. So, he predicted the same results for Conditions 3-5 as for Condition 2, given that all of these involve an independent NP alongside the reference failure NP. In contrast, Lasersohn only predicted a higher number of rejections in Condition 3. It follows from his theory that the presence of a potentially verifiable independent NP (as in Condition 2) should not be enough to influence the judgment. ${ }^{11}$ (He remained agnostic with respect to the relevance of topicality.) Strawson and Reinhart, in contrast, suggested that the presence of an independent potentially verifiable NP was relevant, but only when it would actually be chosen as the topic NP. Whether this would be the case in Conditions 2 and 3 is a matter of chance, or in fact potentially not likely, given the general tendency to regard subject NPs as topics. According to them, a true contrast is only expected between Conditions 4 and 5 , where topicality is controlled for.

Conditions 6-10 corresponded to Conditions o, 2-5, respectively, but involved sentential negation. We were prompted to include negative sentences in our study by results of previous pilot studies showing a general tendency for participants to assign FALSE-judgments to our baseline condition, Condition o. We wanted to investigate whether using negative sentences provides a better opportunity to measure 'squeamishness'. Our core assumption was that if a FALSE judgment in our positive conditions arises not on the basis of the utterance being considered semantically false, but rather as a result of some kind of pragmatic rejection of a particular statement, then

more directly related to their (left-)dislocated syntactic status. In the former case, the same effect (i.e. the expected difference between Conditions 4 and 5) should be replicated by other constructions that determine the information status of the NPs in question as topical. In the latter case, one would expect to find similar effects in other constructions where the NP would appear in a syntactically marked or salient position, even in the absence of topical interpretation. We leave this issue open here for further research.

11 It is conceivable, although we tried to avoid this, that participants would have direct knowledge about the independent NP in the predicate position of the items in Condition 2, i.e. they would know who was and was not on a state visit to Australia that week. In such a case, we would effectively test Lasersohn's prediction without us knowing. We chose our test items carefully to make it extremely unlikely that this would hold for all participants and all items. Thus, even in the unlikely event that some participants have relevant knowledge in some items, the bulk of our test items would still be testing von Fintel's predictions. 
the judgment of the negation of that utterance should not turn into a TRUE judgment. This is because rejecting an utterance does not necessarily equal a willingness to accept its negated version. So, if the reason why (15a) is judged to be FALSE is not because it has the semantic value o, then (15b) should not be judged as TRUE:

(15) a. The king of France is bald.

b. The king of France is not bald.

Thus, a low proportion of TRUE judgments was expected for Condition 6 by all the truth-value gap theories reviewed here. ${ }^{12}$ Von Fintel's theory would be supported if we were to get a higher number of TRUE judgments in Condition 7, the negated version of Condition 2, compared to Condition 6 , the negated version of Condition o. This is because he predicts that definitive truth-values are more easily accessible to the hearer if another NP is present in the utterance. Lasersohn predicted a higher number of TRUE judgments in Condition 8, the negated version of Condition 3, than our negative baseline, Condition 6. Finally, Reinhart/Strawson predicted higher number of TRUE judgments in Condition 10 than in Condition 9, which are the negated equivalents of Conditions 5 and 4 , respectively.

Table 2 summarises the predictions. As we have spelled out above, all three truth-value gap theories agree that sentences like The king of France is bald, i.e. Condition o, our baseline condition, should lead to truth-value gaps and thus CAN'T SAY judgments. This condition serves a background against which we evaluate our remaining conditions. Since no presuppositions are present in Condition 1, all theories predict FALSE judgments for these. The theory of von Fintel predicts a higher number of FALSE judgments in Condition 2, 3, 4, 5 than in Condition o and no difference among Conditions 2, 3, 4, 5. Lasersohn predicts a higher percentage of FALSE answers for Condition 3 than Condition o, and Strawson and Reinhart predicted that items in Condition 4 lead to truth-value gaps, while those in Condition 5 are expected to be judged FALSE. In the negative base-line condition, a low number of TRUE judgments are expected in all three truth-value gap theories. In contrast, the proportion of TRUE judgments is expected to be higher in Conditions 7-10 than in Condition 6 by von Fintel; Lasersohn predicts the

12 We discuss possible alternative interpretations of our findings in section 5.2 including the neo-Russellian position. 
Experimenting with the king of France

same to occur only in Condition 8. Finally, Strawson and Reinhart expect a higher number of TRUE judgments in Condition 10 than in Condition 9.

\begin{tabular}{llll}
\hline Conditions & von Fintel & Lasersohn & Strawson/Reinhart \\
\hline Co base line & CAN'T SAY & CAN'T SAY & CAN'T SAY \\
C1 control & FALSE & FALSE & FALSE \\
C2 'von Fintel' & FALSE & as in Co & FALSE/CAN'T SAY \\
C3 'Lasersohn' & as in C2 & FALSE & FALSE/CAN'T SAY \\
C4 'KOF=topic' & as in C2 & - & CAN'T SAY \\
C5 'other NP=topic' & as in C2 & - & FALSE \\
\hline C6 'negative baseline' & CAN'T SAY & CAN'T SAY & CAN'T SAY \\
C7 'neg von Fintel' & TRUE & CAN'T SAY & TRUE/CAN'T SAY \\
C8 'neg Lasersohn' & as in C6 & TRUE & TRUE/CAN'T SAY \\
C9 'neg KOF=topic' & as in C6 & - & CAN'T SAY \\
C10 'other NP=topic' & as in C6 & - & TRUE
\end{tabular}

Table 2 Summary of the predictions for the different conditions, with the conditions that were designed to test the various theories shaded. (Condition numbers refer to the same example types as in Table 1)

\section{Results}

All but one of our participants successfully finished the task. The participant who failed to complete the task was excluded. We calculated the proportion of TRUE, CAN'T SAY and FALSE responses for each condition. This is plotted for ease of reference in Figure 1. A table with standard deviations indicative of speaker variation is provided in the Appendix.

From a bird's eye view, we can see that the tendency of participants to judge positive sentences as FALSE already observed in pilot studies was replicated in the main experiment. The proportion of CAN'T SAY responses in our base line condition, Co was less than $20 \%$. This was not predicted by any of the three theories tested here. The proportion of TRUE responses in our negative baseline was $21.3 \%$. Although, as we will see below, this is significantly lower than in the other negative conditions, it is important to note that the theories compared here did not predict any TRUE judgments in this condition. We will discuss these findings further in Section 5.2, where we interpret our results.

We compared the proportion (\%) at which subjects replied FALSE to the test items in Conditions o-5 with ANOVA, following checks for normal distri- 


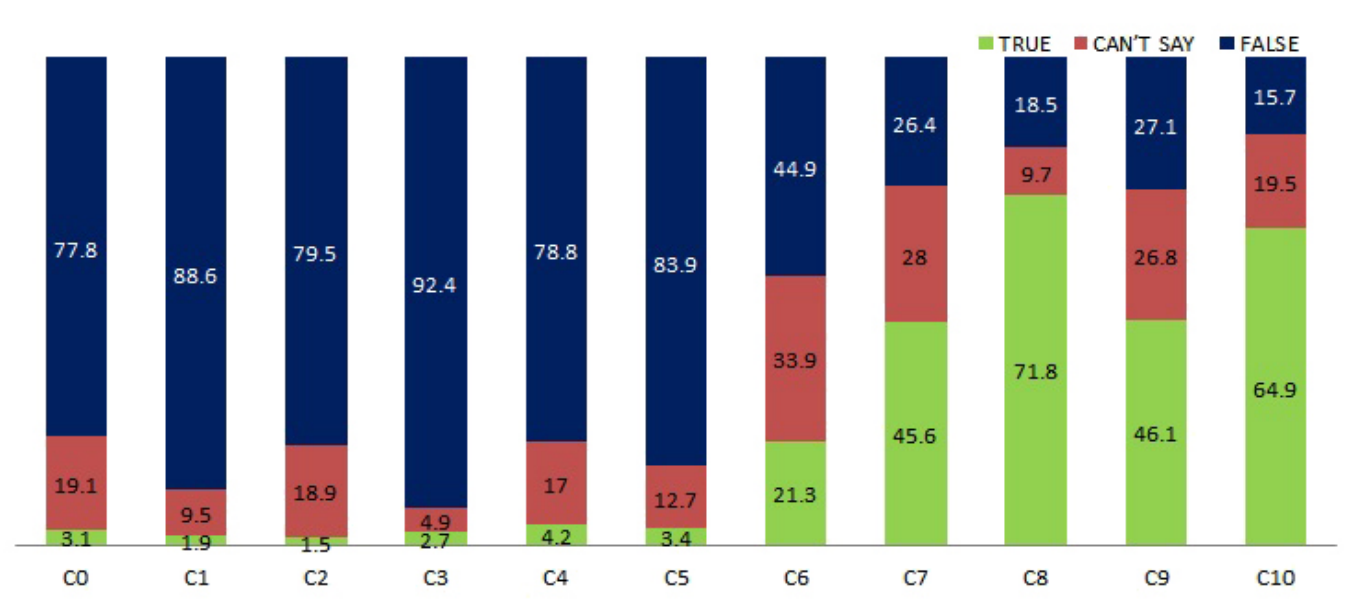

Figure 1 Proportion of TRUE/ CAN'T SAY/ FALSE responses in each condition

bution and homogeneity of variance. We found only weak or nearly significant differences between any of the Conditions $0-5$ ( $>0.05$, Bonferroni post-hoc test), i.e. the positive conditions. Our subjects said FALSE to most of these most of the time. None of the conditions (Co- $\left.\mathrm{C}_{5}\right)$ differed significantly from our FALSE-fillers (plotted in Figure 2 as Condition 13) either.

Since there was no significant difference in the percentage of FALSE judgments between any of the conditions o-5, we could not verify either von Fintel's predictions (Co vs. C2), nor Lasersohn's predictions (Co vs. C3) nor an effect of topicality ( $\mathrm{C}_{4}$ vs. $\mathrm{C}_{5}$ ) by looking at positive sentences.

The negated versions of Conditions o, 2-5, namely Conditions 6-10 turned out to be more informative. We compared the proportion (\%) of TRUE responses in these conditions with ANOVA, (Bonferroni post-hoc test). As Figure 3 illustrates, we found that speakers responded TRUE at a significantly higher proportion to the items in Conditions 7, 8, 9, 10 than to the items in Condition 6 ( $\mathrm{p}<0.003$ in all cases), our negative base-line. The significant difference between the proportion of TRUE responses in Conditions 6 and 7 (and also 6 vs. 8, 9, 10) indicates that von Fintel's predictions are borne out. The significant difference between Conditions 6 and 8 supports Lasersohn's theory. Condition 8 also differed significantly from Condition 7 ( $\mathrm{p}=0.0012)$. In addition, we also found a significant difference $(p=0.037)$ between the number of TRUE responses between Conditions 9 and 10: speakers responded with TRUE at a significantly higher proportion to Condition 10 than to Condition 9, which is in accordance with Strawson/ Reinhart's predictions, and indicates 
Experimenting with the king of France

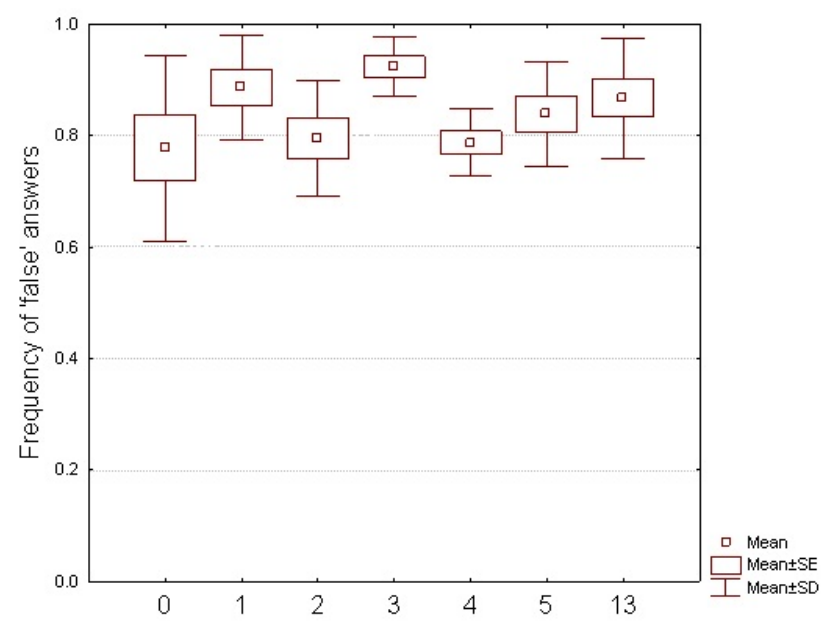

Figure 2 Frequencies of FALSE answers for conditions 0-5, and 13. Box represents standard errors of the sample, whiskers standard deviation. None of the conditions o-5 differ significantly from each other, nor from the control condition 13 for which we expected FALSE answers.

that topichood also plays a part in subjective evaluations of the truth of sentences with reference failure definite descriptions. The difference between conditions 7 vs. 9 and 8 vs. 10 was not significant ( $p>0.05$ ).

When comparing Conditions 6-10 with TRUE-fillers, we found that all the conditions 6-10 (except condition 8) differed significantly from true controls as well, even if weakly $(\mathrm{p}<0.045)$.

Finally, a post hoc comparison of the number of FALSE responses to Condition o and Condition 6 (i.e. the negated version of Condition o) revealed a significant difference. In other words, our subjects were much more likely to reply FALSE to the examples in Condition o than to the examples in Condition 6. $(t$-test $\mathrm{p}=0.0002$, post hoc comparison) (see also Figure 1$) .{ }^{13}$

13 The statistical significance of our data shows that the group of participants as a whole showed the effects we discuss below. At the same time, there seems to be some interesting individual variation in our data. These might signal personal strategies to deal with the experimental task. In particular, there were 4 participants for whom the mean proportion of FALSE judgments for the positive test conditions was $94.4 \%$, while the mean proportion of TRUE judgments for the negative conditions was $83.8 \%$. Even for C6, our negative base-line condition, these 4 individuals gave a TRUE judgment $84.4 \%$ of the time. (They judged Co FALSE $96.88 \%$ of the time). Another discernible group involves 7 individuals who chose CAN'T SAY at least 3 out of 8 times on our positive base-line (Co), but not on our control, $\mathrm{C} 1$. We could interpret such behaviour as the one closest to the original prediction of the 


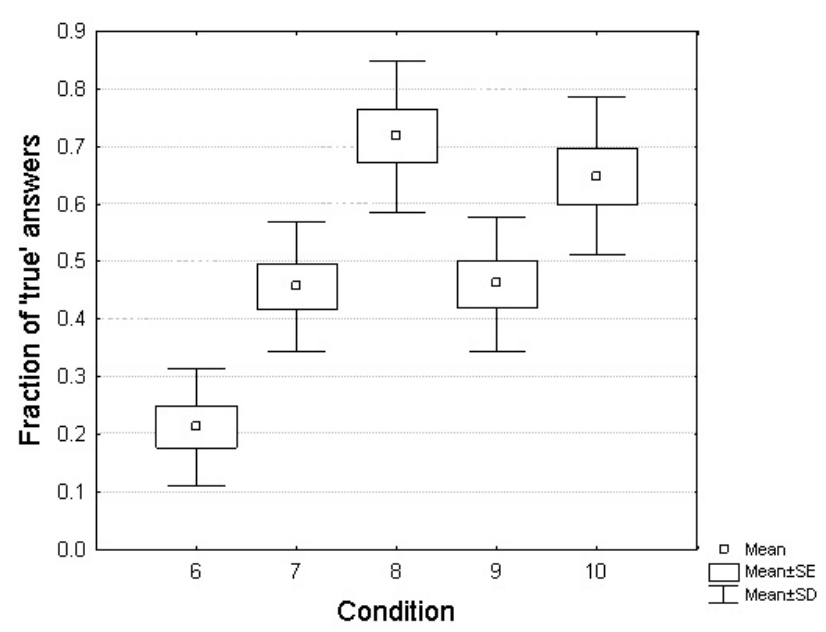

Figure 3 Frequencies of TRUE answers for conditions 6-10. Box represents standard errors of the sample, whiskers standard deviation. Condition 6 differs significantly from all other conditions $(p<0.003$, ANOVA, Bonferroni post-hoc test), condition 10 differs significantly from condition $9(\mathrm{p}=\mathrm{0.037})$, condition 8 differs significantly from condition $7(\mathrm{p}=\mathrm{0.0012})$

\section{Discussion}

\subsection{Predictions borne out by negative conditions C6-C1o}

Let us start by comparing our findings with the predictions stated above and summarised in Table 2. None of the predicted differences were found among the positive conditions $\left(\mathrm{Co}_{-} \mathrm{C}_{5}\right)$. We will discuss this below. The negative conditions were more informative.

In particular, we found that von Fintel's predictions were borne out: Condition 7 (and also Conditions 8, 9 and 10) received a significantly higher proportion of TRUE responses than Condition 6. So, people were more

truth-value gap theories: these people were 'squeamish' about assigning a truth value even in the positive conditions and indicated their squeamishness by using the CAN'T SAY label. Although this sample is too small for a statistical analysis, we can report that the proportions of FALSE responses by these participants tallied with the predictions (summarised in Table 2) for all the positive conditions: Co (base line) 50\%, C1 (control) $75 \%, \mathrm{C}_{2}$ (von Fintel) $67.9 \%, \mathrm{C}_{3}$ (Lasersohn) 89.3\%, C4-C5 (Strawson/Reinhart) 53.6\%-73.2\%. Note further that, as expected, the same people chose the TRUE label in only $12.5 \%$ of the time in our negative base line condition C6, compared to the overall proportion of TRUE for C6 for all the participants, which was $21.3 \%$, as shown in Figure 1. For precision's sake, the proportion of TRUE responses for these 7 participants for the remaining conditions were $C_{7} 44.6 \%$, C8 69.6\%, C9 50\% and C10 57.1\%. 
ready to assign a truth-value if alongside the reference failure NP there was also another NP present that could provide a foothold for verification. We will call this the 'independent NP'-effect for ease of reference. We also found support for Lasersohn's theory: Condition 8 differed significantly both from Condition 6 and Condition 7. Thus there was a significant difference between the proportion of TRUE responses to Condition 7, the 'pure' von Fintel condition, and Condition 8, the one that aimed to test Lasersohn's theory. Lasersohn proposed that inferential reasoning may supply a truthvalue to statements with referentially challenged NPs if the speaker has actual knowledge that would not be consistent with the truth or falsity of the statement, irrespective of whether the existential presupposition of the NP is met. For ease of reference, we will call this the 'actual knowledge'-effect. ${ }^{14}$

Recall that von Fintel argued against the necessity of having relevant actual knowledge about the other NP. According to him, it is enough that such knowledge would be potentially available. In the example in (12-C7), it is unlikely that subjects know who was or was not on a state visit to Australia this week. Nevertheless, the fact that they could go and find out is enough to commit to a truth-value label. We suggest that that the actual knowledge-effect appears to be larger than the independent NP-effect because there are indeed two separate factors, and both measurably influenced truthvalue judgments. ${ }^{15}$ For the independent NP-effect, it is enough that an NP

14 Recall that our Lasersohn items were individually paired with a filler item ensuring that participants have the necessary knowledge base to support a Lasersohnian inference. The proportion of TRUE responses for these fillers was $85.5 \%$. Comparison of the proportion of TRUE responses for these fillers and the C8 test items revealed that participants were more likely to choose the TRUE label for a C8 item if they also gave a TRUE response to the relevant filler items $\left(x^{2}=6.678, \mathrm{Df}=1, \mathrm{p}<.01\right)$. In other words, participants who did not reply TRUE to the relevant fillers were less likely to reply TRUE to our Lasersohnian test items than those participants that replied TRUE to the fillers. This is in line with Lasersohn's predictions: the proportion of TRUE responses in C8 correlates with the proportion of TRUE responses in the relevant fillers.

15 Another theoretical possibility, albeit one that we disprefer, is that there are no separate independent NP-effect and actual knowledge-effects. Rather, both sets of results (i.e. Condition 7 vs. 6 and Condition 8 vs 6) are due to the actual knowledge-effect. The difference in the size of the effects would then simply be due to a difference in the actual knowledge of the speakers. In addition, as suggested by an anonymous reviewer, one further factor that may have contributed to the difference between the results of Conditions 7 and 8 is that by testing for relevant knowledge with respect to Condition 8 items by individually paired fillers, we in fact rendered that piece of knowledge highly accessible and salient. We consider this explanation for the difference highly unlikely however, given that examples in Condition 7 were consciously constructed to test knowledge that speakers would be unlikely 
is present on the basis of which it would be possible to verify the sentence (given some appropriate knowledge dataset, say Wikipedia). For the actual knowledge-effect, the properties of the NP provide a basis for verification given the speaker's actual knowledge base. This explains the finding that the actual knowledge-effect is stronger: Our sentences that satisfied Lasersohn's criteria also satisfied von Fintel's criteria, but not the other way around. So, Condition 8 in fact tested both effects, while Conditions 7 (and 9) only tested one, the independent NP-effect.

We also found that there was a topic-effect: there was a significantly higher number of TRUE responses in Condition 10, where an existentially sound NP was topicalised, (16b), than in Condition 9, where the NP with referential failure was topicalised (16a).

(16) a. The king of France, he wasn't invited to have dinner with Sarkozy.

b. Sarkozy, he wasn't invited to have dinner with the king of France.

Strawson/ Reinhart proposed that topicality affects truth-value judgments. In particular, in (16a) they would expect a truth-value gap, while in (16b), where the reference failure NP is not in topic position they expect TRUE judgments. Our results for Conditions 9 and 10 are consistent with their prediction (see discussion in Section 5.3 for our explanation for the effect found).

Note that there was no significant difference in the proportion of TRUE responses between Conditions 7, the von Fintel condition, and Condition 9. So, it seems that topicalising the reference failure NP does not have a detrimental effect over and above having such an NP as the subject of the sentence. However, this may be due to a tendency, noted by Reinhart (1981: Fn 13), for subject NPs in English to act as sentence topics. Note further that there was a significant difference between the proportion of TRUE responses between Conditions 9 and 6. But this is due to the fact that our sentences in Condition 9 involve an independent NP alongside the reference failure one and are thus subject to the independent NP-effect. There are no such NPs in Condition $6 .{ }^{16}$

to have: e.g. who was or was not on a state visit to Australia; who is or is not good friends with Vladimir Putin etc. (See Appendix 1 for a full set of examples.) So, the fact that there is any difference between the results of Condition 6 and 7 would be surprising.

16 Thus we do not have data about topicality that are not also independent NP-effect data. Therefore, strictly speaking, we can only conclude that topicality is relevant when there is also an independent NP-effect. This is because it is hard to find data that do not contain an extra independent salient NP and in which the reference failure NP is definitely not in topic. To make sure the target NP is not in topic, it is best to topicalize something else. We could 
Experimenting with the king of France

Let us also note that contrary to his claim, von Fintel's argument about (4), repeated below for convenience, does not show that there is no topic effect. It only shows that the effect of another salient NP based on which the sentence could be verified (i.e. the independent NP-effect) is stronger than whatever topic effect there is (if there is one), and can make a sentence seem false, despite presupposition failure. In fact, we may presume that the speaker knows whom (s)he has breakfast with that morning, so the utterance in fact satisfies Lasersohn's criteria (i.e. it is subject to the actual knowledge-effect). Recall that almost $72 \%$ of our participants accepted negative Lasersohnian sentences. Given the strength of this effect, it is even less surprising that our pragmatic strategy that provides enough grounds to reject a sentence with a referentially unsound NP is not swayed by the topicality of that NP.

(17) Let me tell you about my friend, the king of France. I had breakfast with him this morning.

So, the statement in (17) can be rejected based on the speaker's knowledge about whom (s)he had breakfast with that morning. But this still leaves open the possibility that topicality also has an effect, albeit a weaker one than the presence of some salient entity based on which the sentence can be verified given the speaker's knowledge base.

Nevertheless, von Fintel's other argument about the presence of presuppositions in non-topical NPs still stands. Thus while we agree with Strawson/Reinhart that topicality is an important factor that influences truth value judgments, we do not think it is an argument for or against definite descriptions being presuppositional in non-topical positions.

A final point we would like to add regarding our items in Conditions 9 and 10 is that these involved left dislocated NPs, which is arguably a topicalisation construction, however, a very specific one. It is possible that it is the dislocated nature of the NPs, and not their topical status that contributed the effect. We return to this issue briefly in section 5.3 where we discuss the relative import of verification and topicality for truth-value judgments.

have perhaps topicalized NPs that cannot serve as a foothold for verification, but that in turn could have introduced a topic effect on the reference failure NP. 


\subsection{Explanatory strategies: The positive vs. the negative conditions, variation $^{17}$}

Overall, we did find variation among the different sentential contexts, but only in the negative conditions. Thus while there were no significant differences when comparing the frequency of FALSE answers to the positive conditions o-5 (see Figure 2), we found significant differences when comparing the frequency of TRUE answers to conditions 6-10, the negated versions of the previous (see Figure 3). Also, the number of FALSE responses to Condition o differed significantly from Condition 6 , which was the negated version of Condition o: our subjects were much more likely to reply FALSE to the examples in Condition o than to the examples in Condition 6.

In our discussion below we try to find answers to two fundamental questions: (a) How can the various theories of definite descriptions explain the difference we found between the positive and the negative conditions? (b) How can they explain the variation that we found among the different sentential contexts in the negative conditions?

Russell The result that speakers chose FALSE for all the positive conditions seems to support the Russellian view, as this is just what is predicted on this view. Nevertheless, the results we found in the negative topic conditions present some difficulties for this view. Let's look at the results in Condition 6 first. The Russellian view predicts that speakers should judge sentences in this condition either as straightforwardly TRUE, or as straightforwardly FALSE, depending on how they construct the scope of negation. Compare the representation of The king of France is not bald:

a. not ([the $\mathrm{x}$ : $\mathrm{x}$ is the King of France] bald (x)) TRUE

b. [the $\mathrm{x}$ : $\mathrm{x}$ is the King of France] not (bald(x)) FALSE

If negation is constructed as having wide scope over the existential quantifier, as in (18a), the sentence is predicted to be TRUE. On the narrow scope construal of negation (18a), the sentence is predicted to be FALSE. The results we got for Condition 6 are close to chance, and this might be explained by assuming that speakers construct negation either as low scope or as narrow scope, and the mixed pattern reflects their uncertainty of which scope to

17 This section was substantially revised thanks to the helpful comments of anonymous reviewers and the editors of S\&P. 
choose. Thus on this view there might be a principled reason to explain the asymmetry we found among the positive and the negative conditions. So far, so good.

The question is how the Russellian view can predict the systematic variation in conditions 6 to 10. The upshot of our discussion is this: though the variation does not follow from the Russellian account per se, if we add some pragmatic mechanisms and biases along the lines sketched by Lasersohn and von Fintel on top of the neo-Russellian semantics, this view is compatible with a significant part of the results we got. What we found is that in the independent NP (von Fintel), actual knowledge (Lasersohn) and topic conditions (Reinhart/Strawson), speakers judged the test sentences as TRUE significantly more times than in Condition 6. To explain this, Russellians would have to argue that in these sentential constructions even though the utterance is scopally ambiguous, the wide scope construal of negation is favoured for some reason. In the actual knowledge condition for example, the presence of extra background information (e.g. that Carla Bruni is married to Sarkozy) might bias the speakers towards the wide scope negation (TRUE) construal of the sentence (in the example below, speakers might feel that the sentence says something true about Carla Bruni). (Whereas the information about Carla Bruni does not help in evaluating the truth of (19b).)

(19) The king of France is not married to Carla Bruni.

a. not([the $\mathrm{x}: \mathrm{x}$ is the King of France] married-to-Carla-Bruni (x)) TRUE

b. \#[the $\mathrm{x}$ : $\mathrm{x}$ is the King of France]not(married-to-Carla-Bruni(x)) FALSE

Presumably, the same explanation could be given in the case of the independent NP conditions. The difference between the two topic conditions (conditions 9 and 10) might be a bit more difficult to explain. On the one hand, the fact that in Condition 10, where a different referential NP is topicalised from the one showing reference failure, speakers tend to reply with more TRUE answers than in Condition 6 might have an explanation: perhaps topicalised constituents prefer to take scope just above negation (though of course a detailed proposal would have to be worked out for why this has to be so).

(20) Sarkozy, he was not invited to have dinner with the King of France.

a. Sarkozy, not ([the $\mathrm{x}: \mathrm{x}$ is the King of France] he was invited to have dinner with (x)) 
b. \#Sarkozy, [the $\mathrm{x}$ : $\mathrm{x}$ is the King of France] not (he was invited to have dinner with $(\mathrm{x})$ )

However if this is the case, than the same should happen in the examples in Condition 9, where a reference failure NP is topicalised: this would predict that this NP is not in the scope of negation, which results in a false sentence. This then should bias speakers against a TRUE judgment in the case of Condition 9. To some extent this prediction is borne out, in the sense that we got significantly less TRUE answers in condition 9 than condition 10. However, the frequency of TRUE answers in Condition 9 is still significantly higher than in Condition 6 , which is quite puzzling because if topicalised constituents prefer to take scope above negation, we should expect the opposite: the number of true responses in Condition 9 should be lower than in Condition 6.

Thus it seems to us that although overall our results can be made compatible with (neo-)Russellian view if we assume that pragmatic biases might favour the wide scope construal of negation in some cases, the results that we found in the topic conditions $\mathrm{C} 9$ and C1O, as compared to Condition 6, are still somewhat puzzling for this view.

Strawson The purely semantic version of the truth-value gap account predicts that all the sentences in conditions o, 2-10 should be truth-valueless. This semantics however, as suggested by Strawson (1964), Reinhart (1981), Lasersohn (1993), von Fintel (2004) and others, should be complemented with pragmatic considerations, which might give rise to intuitive judgments of FALSE or TRUE even where the semantics predicts a truth-value gap. This literature mostly concentrates on differences in intuitions regarding positive sentences (with the exception of Lasersohn). From this point of view, it is interesting that our subjects chose FALSE in all our positive conditions.

Nevertheless, this result is not necessarily a fatal blow to truth-value gap theories. This is because we do not know for sure how our subjects interpreted the response option FALSE. For all we know, pressing the FALSE button could mean for them 'I do not think it is true' or 'I am rejecting this sentence' rather than 'I think this sentence is false'. This would mean our design did not properly test for presupposition failure as opposed to falsity. Another (related) possibility is that people do not even have reliable intuitions distinguishing falsity from lack of truth-value/presupposition failure (cf. Soames 1976, Neale 1990 e.g.), thus we attempted to test something 
that cannot be tested anyway. (But note that this second position also undermines the overall legitimacy of any truth-value gap theory that is based on differences in introspective judgments, such as Lasersohn, von Fintel and others). Either way, presupposition failure might be assumed to lead people to press the FALSE button, rather than CAN'T SAY, and so our results for the positive conditions might be compatible with the spirit of the truth-value gap approach, if not with Strawson's own judgments.

An interesting aspect of our results is the asymmetry between the positive and the negative conditions: we got the response FALSE to all our positive conditions, while the negated versions of these were not judged as uniformly TRUE. Let us first compare Condition o (our baseline) and its negated version Condition 6. What is important to note is that for Condition 6 we did not get a high number of FALSE replies (which could be expected if speakers were to again overapply FALSE to truth-valueless sentences, as we proposed to Condition o above), nor did we get a high number of TRUE replies. One possibility, pointed out to us by an anonymous reviewer, is that the mixed result we get for Condition 6 is the result of speakers optionally performing local accommodation under negation (cf. Heim 1983, e.g.). ${ }^{18}$ For concreteness, let us assume that local accommodation is performed by applying an assertion (A) operator under negation à la Beaver \& Krahmer (2001). The operator A turns presuppositions into assertions, in effect cancelling them. Since local accommodation is optional, when evaluating the sentences in Condition 6 such as (21), speakers might understand it as (21a) or (21b), i.e. with or without local accommodation: ${ }^{19}$

18 There are multiple ways of analyzing the potential source of ambiguity: it might reflect the ambiguity of negation (normal vs. metalinguistic negation/denial) or the possibility of local accommodation, or the presence of a presupposition cancelling operator à la Beaver \& Krahmer 2001 or Fox 2012 etc. The choice among these is not important for our purposes, but see e.g. Geurts 1998 and L. Horn 1989 for discussion.

19 An anonymous reviewer notes that it is conceivable to assume a version of the operator theory in which the presupposition cancelling A operator can also apply at the matrix level. This would derive a third semantic representation to (21) as well, one in which the A operator is applied above negation. However, this theory would also predict two representations for sentences in Condition o, a presuppositional and a non-presuppositional one. Yet our responses to Condition o did not differ statistically from our responses to the nonpresuppositional examples in Condition 1 . This means that the small variation we observe in the data cannot be safely assumed to be anything other than noise. Hence, we do not have evidence for ambiguity in the case of Condition o. For this reason we believe a version of the operator theories that allows matrix insertion of A is not compatible with our overall findings. 
Márta Abrusán and Kriszta Szendrői

(21) The king of France is not bald
a. Not (A (the king of France is bald))
TRUE
b. Not (the king of France is bald)
truth-valueless

This potential ambiguity might explain the mixed results we got for Condition 6, in contrast with Condition o: in the former case speakers might be uncertain whether or not to apply local accommodation. The same option however is not present in Condition $0 .^{20}$ Thus, truth-value gap theories need to assume the possibility of local accommodation (or some similar stipulation) in order to explain the difference between Conditions o and 6 .

Predicting the variation (in the negative conditions) or the lack of variation (in the positive conditions) among the different sentential contexts could go as follows. As for the sentences in the positive Conditions 2-5, these are judged to be FALSE either for the same reason as Condition o, or because of Lasersohn's/von Fintel's idea according to which speakers opt for FALSE in order to avoid the conversational impasse created by a presupposition failure, but only if they have independent reasons to reject the sentence. The variation in the negative conditions could be explained as follows. Suppose, following Laserson and von Fintel, that speakers are more inclined to judge truth-valueless sentences as pragmatically TRUE or FALSE if they have independent information based on which the sentence can be verified or an independent foothold for verification is present. ${ }^{21}$ This predicts that they should reject sentences in Conditions 2-5 and accept sentences in conditions 7-10. If the negative sentences are ambiguous between readings with or without local accommodation of the presupposition, the independent footholds in the sentence that facilitate accepting it might bias our subjects towards the TRUE answer, i.e. the one where the presupposition has been accommodated. Alternatively, and perhaps more in line with the original proposals in Lasersohn and von Fintel, even for the reading where the presupposition is not locally accommodated, the presence of pragmatic clues for verification allow speakers to ignore presupposition failure and arrive at an intuitive truth value. Similarly, there are two possibilities in the case of topic conditions. One is that when a non-reference failure NP is topicalised,

20 The difference between Conditions o and 6 might perhaps also be explained by assuming four-valued logics, with values 1,0 , \#, *, where \# is interpreted as 'neither true nor false' and * is interpreted as 'both true and false' (see for example Visser 1984). In this case one could say that speakers map \# but not * to FALSE.

21 von Fintel (2004) does not discuss negative cases, so what we assume is what seems to us to be a sensible extension of the reasoning presented there. 
Experimenting with the king of France

there is a bias in favour of the reading that involves local accommodation (relative to an utterance where the reference failure NP is topicalised) because the topic phrase can serve as an independent foothold for verification. A second possibility is that topicalising a referentially sound NP makes it easier for speakers to pay attention to this NP and verify the sentence based on it. This in turn facilitates the independent NP-effect even in the absence of local accommodation. (More on the connection between the verification approaches and the topic condition in Section 5.3)

Thus we did find indirect evidence that the mechanisms for verification outlined by Lasersohn and von Fintel (as well as topicality) are indeed relevant factors for the intuitive truth judgments that people have, although we believe that the reasoning speakers use might be different from that proposed by Lasersohn and von Fintel (reviewed in Section 2).

Stalnaker Stalnaker (1974) has proposed a pragmatic theory of presuppositions. According to this theory, for an utterance of a sentence with a definite description to be felicitous, the speaker has to assume that an individual satisfying the definite description exists (and, ideally, that his interlocutors share this belief, etc). Since presupposition on this theory is only a pragmatic requirement for a felicitous utterance and has no truth-conditional consequences, the fact that a sentence requires a presupposition (in the above sense) is compatible with it also entailing the content of the presupposition. (see Stalnaker 1974 where he suggests this is indeed the case). Given this, on the pragmatic presupposition view sentences with definite descriptions can be assumed to have a (neo-)Russellian semantics, on top of which they also require that the pragmatic presupposition induced by the definite descriptions be satisfied by the context. ${ }^{22}$

First, take the contrast between the positive and the negative sentences. As for the positive sentences in Condition o, speakers say these are false, because they are indeed semantically false, and the fact that these sentences at the same time exhibit a presupposition failure makes them infelicitous, but

22 In this discussion we concentrate on Stalnaker's original theory. Many other pragmatic or partly pragmatic theories of presuppositions have been proposed that are partly similar to Stalnaker's (cf. Atlas 1977; Karttunen \& Peters 1979; Abbott 2000; Simons 2001; Gazdar 1979; Schlenker 2008, 2009; among others). Further, in the last ten years or so, an interesting discussion has emerged around the question whether the uniqueness and/or the familiarity inferences of definite descriptions can be derived pragmatically (cf. e.g. Abbott 1999, Szabó 2000, Roberts 2003). For reasons of space, we do not discuss all these individual theories. 
not "unfalse". Therefore speakers do not have a reason not to press the FALSE button. As for the sentences in Condition 6 (the negative baseline sentences), although these are semantically true, they are also pragmatically infelicitous because the presupposition they require clashes with some propositions in the context set. Suppose TRUE implies a commitment to add the sentence to the context set: this suffices to prevent people from saying that such sentences are TRUE. Adding such sentences to the context set would render it incoherent, so speakers might be tempted to avoid saying that they are true.

As for the lack of variation among the different sentential contexts in the positive conditions, these could be explained in the same way as Condition o, or as in the neo-Russellian theory. The variation in the negative conditions can be explained as well: In these cases (Conditions 7-10) there is a good pragmatic strategy based on which the presupposition failure can be ignored, and therefore the sentences with negation that are semantically true will be felt as pragmatically TRUE as well. This predicts the difference we found between Condition 6 vs. conditions 7, 8, 9, and 10. More precisely, sentences in Condition 7 might be judged as TRUE because the presence of an independent noun phrase based on which the sentence can be verified might provide enough grounds for speakers to ignore the presupposition failure and judge the sentence as pragmatically felicitous. (This is the independent NP-effect). Similar reasoning might be applied in the case of Condition 8, the actual knowledge-effect, where the independently known facts make this effect even stronger. The difference in the topic conditions can be explained as follows. Assume that topicalising a noun phrase is interpreted by speakers as a suggestion to verify the sentence based on this noun phrase, as we propose in section 5.3. When a non-reference failure NP is topicalised, the speakers are more likely to try to verify the sentence based on a noun phrase with an existing referent. This might facilitate ignoring the presupposition failure and arriving at the truth value TRUE. When however a reference failure NP is topicalised, speakers are not better off by first trying to verify the sentence based on this non-existing individual. This predicts the difference in TRUE answers in conditions 9 and 10. Nevertheless, when speakers cannot verify the sentence on a topic constituent they might still try to verify it based on whatever other suitable individual they can find in the sentence: this is why sentences in Condition 9 do not differ significantly from sentences in Condition 7, the condition designed to test von Fintel's theory. 
Experimenting with the king of France

Interim summary Overall, our results underline the importance of the observation, made most clearly by Lasersohn and von Fintel, that semantic truth-value and the felt truth-value intuition might differ. Further, they also establish that pragmatic factors that influence truth-value judgments exist, and should be taken into account by any theory of definite descriptions. There is an effect of an independent salient NP in the sentence (the independent NP-effect), there is an effect of independently known information (the actual knowledge-effect) and there is also a topic effect. However, none of these is the only relevant factor that speakers use when arriving at an intuitive truthvalue judgment. In the remainder of this section we discuss these pragmatic mechanisms a little more and propose that these three mechanisms are not independent, but can be connected.

\subsection{Independent or connected effects? Speculations about topichood and the process of verification}

In the previous sections we have argued that the pragmatic strategies influencing truth-value judgment such as topichood, verification based on salient footholds and independent knowledge indeed exist. In this section we would like to speculate about whether these seemingly different factors can be connected, and reduced to more elementary processes by which sentences are verified, essentially supporting von Fintel's (2004) and Lasersohn's (1993) overall approach (even if not necessarily word-for-word their proposals).

Recall from Section 2 that von Fintel noticed certain properties that entities that can serve as a foothold for verification have to satisfy: they need to be independently salient and they need to be such that it makes sense to observe their properties to decide about the truth-value of a sentence. As was mentioned in Section 2, von Fintel argues there is a difference between (22a) and (22b): the first is a false statement, since in this case the accident could serve as a foothold for verification, but the latter is felt to be neither true nor false, because in this case, intuitively, it is not an accessible property of the accident whether the king of France has heard about it.

(22) a. The king of France died in the car accident on the turnpike last night.

b. The king of France has heard about the car accident on the turnpike last night. 
Admittedly, what exactly distinguishes (22a) from (22b) is rather vague, and von Fintel does not provide clear diagnostic criteria for what can serve as a foothold for verification. We are not in the position to do that either. ${ }^{23}$ Nevertheless, let us call the contextually salient entity that we use to assess the truth or falsity of a particular statement the semantic pivot, or just pivot for short. ${ }^{24}$ Pivot, then, is a notion that is relevant for the process of verifying/falsifying the sentence. Thus pivothood is a semantic notion, but it is not simply concerned with the abstract meaning of the sentence, but rather with the process of understanding it. The process of understanding involves - at least in some cases - the possibility of verifying the sentence. The pivot is what the sentence is semantically about, if such an entity can be found, in this verificational sense of aboutness. ${ }^{25}$ But note that it is not an obligatory element of understanding a sentence: In some cases it might not be possible to identify a unique pivot or indeed any pivot. Further, pivots do not have to be constituents of the sentence. This might be the case in examples with focus marking or clefting, where the set of alternatives provided by focus (or the background question) can serve as the pivot, as in the case of examples similar to (3). ${ }^{26}$

In contrast, topic is a discourse notion. A topic is usually assumed to be either something that is familiar (or given) itself, or something that is an identifiable member of some familiar set of entities (see e.g. Kuno 1972, Givón 1983). Sometimes topic is also equated with the question under discussion (QUD) in a given context (e.g. von Fintel 1994). Others, e.g. Roberts

23 The question seems to be connected to the question of what counts as natural or intrinsic property of individuals. To this question, various answers have been suggested in philosophy literature (cf. Lewis 1986, Langton \& Lewis 1998, Vallentyne 1997, Yablo 1999 among others). Nevertheless it seems to us that these definitions of what is an intrinsic property do not yet give us a way to define what can be a foothold for verification, or pivot in our terms.

24 The word 'pivot' has been already used in the literature: Francez (2007) uses it to refer to the non-locative NP in an existential sentence, e.g. 'the elephant' in the existential sentence There is an elephant in the garden. In the functionalist tradition the notion syntactic pivot denotes the argument of the verb around which the sentence "revolves" (see Foley \& Valin 1984). There are also several explorations on different senses of aboutness, such as Lewis 1988, Putnam 1958, Ryle 1933 etc. We will leave it open for now whether these notions of pivothood and aboutness are connected to ours and if yes, how.

25 We suspect that pivothood, as understood here, might also be the relevant notion for distinguishing nominative and genitive subjects in Russian negative existential constructions discussed extensively by Partee \& Borschev (2004) and references therein. But we do not elaborate this idea here for reasons of space.

26 This was essentially suggested in von Fintel 2004. 
Experimenting with the king of France

(2011) argue for a description in psychological terms: "We say that the entity to which our attention is drawn is the Topic of the utterance" (Roberts 2011: 1). Yet others, e.g. Reinhart $(1981,2006)$, argue that topichood can neither be properly defined by familiarity, nor by discourse-oldness nor by saliency, and conclude that 'topic' means 'the constituent that the sentence is pragmatically about' (cf. also Gundel 1974, Lambrecht 1994). There are thus various approaches to topichood, all of them discourse-based. The unifying notion among these approaches is that topics have to pass the 'Tell me about $a$ ' topic-test: Any constituent $a$ that is introduced by 'Tell me about $a$ ' is definitely a topic. We will not attempt to choose among all the above senses of topic, but we want to stress what topic (under either description) is not: it is not the same as pivothood, introduced above.

A constituent can be a topic, while not being the pivot. This is demonstrated by examples where the reference failure definite is in topic position, and there is another entity in the sentence that can serve as a foothold for verification, as in (23). Here, the noun phrase the king of France does not refer to an entity that can serve as a foothold for verification, yet the hearer reaches a definitive truth-value for such a sentence. Since the reference failure NP cannot be the pivot, as that would lead to a truth-value gap, the pivot can only be the entity denoted by Sarkozy.

(23) As for the king of France, he visited Sarkozy.

Other examples where topics are not pivots are demonstrated by cases of long topic movement, where the topic constituent is moved out from an attitude context, as in (24). Here Bill is clearly the topic, but intuitively it cannot serve as a foothold for verification: to verify this sentence we do not look at the properties of Bill, and see if the property of Peter thinking that he is a fool is among them. We would rather examine the belief state of Peter.

(24) As for Bill, Peter thinks that he is a fool.

However, we would like to claim that topic and pivot also have an important point of connection. It would be natural to assume that if the sentence has a syntactically marked topic, that topic would be the default pivot. This is because topicalising some constituent $c$ raises the salience of $c$, directs the focus of attention to it, structures the context in an appropriate way, (insert your favourite theory here), but in any event it is naturally interpreted as a suggestion to verify the sentence based on $c$. But, as we have seen above, this 
suggestion can be overridden by other considerations: Constituents other than the actual topic can be pivots too, e.g. if the topic is an NP with reference failure, or has been moved out from an attitude context. ${ }^{27}$

Going back to our experimental findings, we propose that the three factors identified by Strawson/Reinhart, Lasersohn and von Fintel that influence truth-value judgments can be connected in the following way. The central notion is verification, more precisely the possibility of verification à la von Fintel. The possibility of verification interacts with speakers' assignment of truth-value judgments either because it helps them ignore a presupposition failure (as von Fintel and Lasersohn originally suggested), or because it biases them towards a favoured reading in case of structural ambiguity. In the terms introduced above, if a sentence contains a potential pivot based on which it could be verified, speakers will naturally tend to focus their attention on this element and therefore find it easier to ignore a presupposition of some other item in the sentence that contradicts their prior beliefs (on the presuppositional accounts), or will be tempted to select a reading that makes the sentence true or false with respect to what it says about the pivot (on the neo-Russellian account).

This effect can be strengthened if either the participants have relevant actual background knowledge about the pivot (as in the actual knowledgeeffect) or if the pivot is topicalised ( $\approx$ Strawson/Reinhart conditions). This latter fact is because topics are default pivots, and hearers tend to verify sentences based on the sentence's topic. In the absence of a potential pivot however, for example when a reference failure NP is the only NP in the sentence as in our negative and positive baseline conditions, neither can presupposition failure be ignored, nor is there any clue to resolve potential ambiguity. ${ }^{28}$ This is why we found mixed results in Condition 6.

Thus overall we agree with von Fintel in dismissing topicality as a determining factor for the presence of existential presuppositions. However, we found that topicality does influence people's truth-value judgments of

27 The idea that constituents other than topics can serve as footholds for verification runs contra to Erteschik-Shir (2007), who proposes that verification always proceeds through the topic. She would predict, contrary to our findings, that sentences in Condition 9 would always lead to truth-value gaps, while sentences in Condition 10 never do.

28 If no possible pivot can be found, there is still the possibility that the sentence might be judged as false based on some information in the common ground, e.g. general laws. This predicts the sentence The king of France cannot run with the speed of 1oomph to be true, in accordance with Lasersohn's theory. (However, we do not actually have data about such sentences.) 
Experimenting with the king of France

sentences with reference-failure noun phrases, contrary to his claim. Nevertheless, once a connection between topics and verifiability is established in terms of our proposal, which states that topics are default pivots, such an effect is in fact expected even on von Fintel's account. Thus verifiability seems to be the determining factor in native speakers' judgments of sentences involving reference failure of noun phrases. Topicality is parasitic on that.

\section{Conclusion}

Definite descriptions with reference failure have been argued in the literature to give rise to different truth-value intuitions depending on the local linguistic context in which they appear. We have confirmed this intuition experimentally, and found that pragmatic strategies dependent on verification and topicalisation, suggested in the context of trivalent/partial theories, indeed play a role in people's subjective judgments. Overall, however, we think that our findings can be explained by combining these pragmatic strategies with any of the three major approaches to definite descriptions, as long as certain provisos are observed: (a) in the case of the Russellian and the Strawsonian approaches some non-trivial assumptions need to be accepted, as was discussed above (b) it has to be assumed that a pragmatic component taking into account topicalization and verification possibilities influences the intuitive truth value that people perceive. We have also suggested a possible way in which the seemingly divergent factors might be given a uniform explanation. 


\section{Appendix 1: Target example sentences}

\begin{tabular}{|c|c|c|}
\hline Items & Item No & Cond \\
\hline The king of France is bald. & 1 & $\mathrm{o}$ \\
\hline The Emperor of Canada is fond of sushi. & 2 & $\mathrm{o}$ \\
\hline The Pope's wife is a lawyer. & 3 & $\mathrm{O}$ \\
\hline The beaches of Birmingham are crowded in the summer. & 4 & o \\
\hline Princess Diana’s daughter is blond. & 5 & $\mathrm{O}$ \\
\hline The Belgian rainforest provides a habitat for many species. & 6 & $\mathrm{O}$ \\
\hline The coral reefs of Brighton attract many tourists. & 7 & $\mathrm{O}$ \\
\hline The volcanoes of Kent dominate the landscape. & 8 & $\mathrm{O}$ \\
\hline France has a king, and he is bald. & 1 & 1 \\
\hline Canada has an emperor, and he is fond of sushi. & 2 & 1 \\
\hline The Pope has a wife, and she is a lawyer. & 3 & 1 \\
\hline There are beaches in Birmingham, and they are crowded in the summer. & 4 & 1 \\
\hline Princess Diana had a daughter, and she is blond. & 5 & 1 \\
\hline $\begin{array}{l}\text { There is a rainforest in Belgium, and it provides a habitat for many } \\
\text { species. }\end{array}$ & 6 & 1 \\
\hline There are coral reefs in Brighton, and they attract lots of tourists. & 7 & 1 \\
\hline There are volcanoes in Kent, and they dominate the landscape. & 8 & 1 \\
\hline The King of France is on a state visit to Australia this week. & 1 & 2 \\
\hline The Emperor of Canada visited Blackpool yesterday. & 2 & 2 \\
\hline The Pope's wife invited Berlusconi for dinner. & 3 & 2 \\
\hline The beaches of Birmingham were visited by David Cameron last month. & 4 & 2 \\
\hline Princess Diana’s daughter is good friends with Vladimir Putin. & 5 & 2 \\
\hline The Belgian rainforest is to the north of Brussels. & 6 & 2 \\
\hline $\begin{array}{l}\text { The coral reefs of Brighton are the favourite holiday spot of Prince } \\
\text { William. }\end{array}$ & 7 & 2 \\
\hline The volcanoes of Kent threaten Canterbury. & 8 & 2 \\
\hline The King of France is married to Carla Bruni. & 1 & 3 \\
\hline The Emperor of Canada resides at 10 Downing Street in London. & 2 & 3 \\
\hline The Pope's wife wrote Pride and Prejudice. & 3 & 3 \\
\hline The beaches of Birmingham hosted the 2010 Football World Cup. & 4 & 3 \\
\hline Princess Diana’s daughter is married to Prince Philip. & 5 & 3 \\
\hline The Belgian rainforest separated East and West Berlin. & 6 & 3 \\
\hline The coral reefs of Brighton sank the Titanic. & 7 & 3 \\
\hline $\begin{array}{l}\text { The volcanoes of Kent produced the ash cloud that disrupted air traffic } \\
\text { in Europe last spring. }\end{array}$ & 8 & 3 \\
\hline
\end{tabular}


Experimenting with the king of France

Items (cont'd)

Item No Cond

The King of France, he called Sarkozy last night.

$1 \quad 4$

The Emperor of Canada, he resides in Blackpool for the summer.

The Pope's wife, she invited Berlusconi for dinner.

The beaches of Birmingham, they were visited by David Cameron last

24

month.

Princess Diana's daughter, she is married to Leonardo di Caprio.

The Belgian rainforest, it is the favourite nature spot of David Attenborough.

The coral reefs of Brighton, they feature in the BBC nature series 'Life on

Earth'.

The volcanoes of Kent, they threaten Canterbury.

Sarkozy, he called the King of France last night.

Blackpool, it is the home of the Emperor of Canada for the summer.

Berlusconi, he was invited by the Pope's wife for dinner.

David Cameron, he visited the beaches of Birmingham last month.

Leonardo di Caprio, he is married to Princess Diana's daughter.

David Attenborough, his favourite nature spot is the Belgian rain forest.

The BBC nature series 'Life on Earth', it features the coral reefs of

4

4

4

64

Brighton.

Canterbury, it is threatened by the volcanoes of Kent.

The King of France isn't bald.

The Emperor of Canada isn't fond of sushi.

The Pope's wife isn't a lawyer.

The beaches of Birmingham aren't crowded in the summer.

Princess Diana's daughter isn't blond

The Belgian rainforest doesn't provide a habitat for many species.

The coral reefs of Brighton don't attract many tourists.

The volcanoes of Kent do not dominate the landscape.

The King of France is not on a state visit to Australia this week.

The Emperor of Canada didn't visit Blackpool yesterday.

The Pope's wife did not invite Berlusconi for dinner.

The beaches of Birmingham weren't visited by David Cameron last month.

Princess Diana's daughter isn't good friends with Vladimir Putin.

The Belgian rainforest is not to the north of Brussels.

The coral reefs of Brighton are not the favourite holiday spot of Prince William.

The volcanoes of Kent don't threaten Canterbury.

The King of France is not married to Carla Bruni.

The Emperor of Canada does not reside at 10 Downing Street in London.

The Pope's wife did not write Pride and Prejudice.

The beaches of Birmingham did not host the 2010 Football World Cup.

Princess Diana's daughter isn't married to Prince Philip.

The Belgian rainforest did not separate East and West Berlin.

The coral reefs of Brighton didn't sink the Titanic.

The volcanoes of Kent did not produce the ash cloud that disrupted air traffic in Europe last spring. 


\begin{tabular}{lrr} 
Items (cont'd) & Item No & Cond \\
\hline The King of France, he did not call Sarkozy last night. & 1 & 9 \\
The Emperor of Canada, he does not reside in Blackpool for the summer. & 2 & 9 \\
The Pope's wife, she did not invite Berlusconi for dinner. & 3 & 9 \\
$\begin{array}{l}\text { The beaches of Birmingham, they were not visited by David Cameron last } \\
\text { month. }\end{array}$ & 4 & 9 \\
$\begin{array}{l}\text { Princess Diana's daughter, she is not married to Leonardo di Caprio. } \\
\text { The Belgian rainforest, it is not the favourite nature spot of David Atten- }\end{array}$ & 5 & 9 \\
borough. & & 9 \\
$\begin{array}{l}\text { The coral reefs of Brighton, they did not feature in the BBC nature series } \\
\text { 'Life on Earth'. }\end{array}$ & 7 & 9 \\
The volcanoes of Kent, they do not threaten Canterbury. & 8 & 9 \\
\hline $\begin{array}{l}\text { Sarkozy, he did not call the King of France last night. } \\
\text { Blackpool, it is not the home of the Emperor of Canada for the summer. }\end{array}$ & 2 & 10 \\
$\begin{array}{l}\text { Berlusconi, he was not invited by the Pope's wife for dinner. } \\
\text { David Cameron, he did not visit the beaches of Birmingham last month. }\end{array}$ & 3 & 10 \\
Leonardo di Caprio, he is not married to Princess Diana's daughter. & 4 & 10 \\
$\begin{array}{l}\text { David Attenborough, his favourite nature spot is not the Belgian rain } \\
\text { forest. } \\
\text { The BBC nature series 'Life on Earth', it did not feature the coral reefs of }\end{array}$ & 5 & 10 \\
Brighton . & 6 & 10 \\
Canterbury, it is not threatened by the volcanoes of Kent. & 7 & 10 \\
\end{tabular}

\section{Appendix 2: Overall proportions of TRUE, CAN'T SAY and FALSE judg- ments}

\begin{tabular}{lrrr} 
Conditions & TRUE & CAN'T SAY & FALSE \\
\hline Condition 0 & $3.1 \%(2.9 \%)$ & $19.1 \%(17.2 \%)$ & $77.8 \%(16.7 \%)$ \\
Condition 1 & $1.9 \%(2.8 \%)$ & $9.5 \%(8.3 \%)$ & $88.6 \%(9.3 \%)$ \\
Condition 2 & $1.5 \%(3.2 \%)$ & $18.9 \%(10.5 \%)$ & $79.5 \%(10.5 \%)$ \\
Condition 3 & $2.7 \%(2.5 \%)$ & $4.9 \%(5.1 \%)$ & $92.4 \%(5.4 \%)$ \\
Condition 4 & $4.2 \%(2.3 \%)$ & $17 \%(7.3 \%)$ & $78.8 \%(6.1 \%)$ \\
Condition 5 & $3.4 \%(1.9 \%)$ & $12.7 \%(7.8 \%)$ & $83.9 \%(9.4 \%)$ \\
Condition 6 & $21.3 \%(10.2 \%)$ & $33.9 \%(9.1 \%)$ & $44.9 \%(8.6 \%)$ \\
Condition 7 & $45.6 \%(11.3 \%)$ & $28 \%(4.1 \%)$ & $26.4 \%(12.4 \%)$ \\
Condition 8 & $71.8 \%(13.2 \%)$ & $9.7 \%(5.7 \%)$ & $18.5 \%(9.6 \%)$ \\
Condition 9 & $46.1 \%(11.6 \%)$ & $26.8 \%(6.3 \%)$ & $27.1 \%(11 \%)$ \\
Condition 10 & $64.9 \%(13.8 \%)$ & $19.5 \%(11.5 \%)$ & $15.7 \%(4.7 \%)$
\end{tabular}

Table 3 Overall proportions of TRUE, CAN'T SAY and FALSE judgments per conditions with standard deviations in parentheses 
Experimenting with the king of France

\section{References}

Abbott, Barbara. 1999. Support for a unique theory of definite descriptions. Semantics and Linguistic Theory (SALT) 9. 1-15.

Abbott, Barbara. 2000. Presuppositions as nonassertions. Journal of Pragmatics 32(10). 1419-1437. http://dx.doi.org/10.1016/So378-2166(99)oo108-3.

Atlas, Jay D. 1977. Negation, ambiguity and presupposition. Linguistics and Philosophy 1. 321-336. http://dx.doi.org/10.1007/BFo0353452.

Atlas, Jay D. 2004. Descriptions, linguistic topic/comment, and negative existentials: A case study in the application of linguistic theory to problems in the philosophy of language. In Marga Reimer \& Anne Bezuidenhout (eds.), Descriptions and beyond: An interdisciplinary collection of essays on definite and indefinite descriptions and other related phenomena, 342-36o. Oxford: Oxford University Press.

Beaver, David \& Emiel Krahmer. 2001. A partial account of presupposition projection. Journal of Logic, Language and Information 10(2). 147-182. http://dx.doi.org/10.1023/A:1008371413822.

Bezuidenhout, Anne \& Marga Reimer. 2004. Introduction to Section III, "Presupposition and truth-value gaps". In Anne Bezuidenhout \& Marga Reimer (eds.), Descriptions and beyond: An interdisciplinary collection of essays on definite and indefinite descriptions and other related phenomena, 307-314. Oxford University Press.

Cresti, Diana. 1995. Indefinite topics. Cambridge, MA: Massachusetts Institute of Technology PhD thesis.

Erteschik-Shir, Nomi. 1997. The dynamics of focus structure. Cambridge University Press.

Erteschik-Shir, Nomi. 2007. Information structure. Oxford University Press. von Fintel, Kai. 1994. Restrictions on quantifier domains. Amherst, MA: University of Massachusetts PhD thesis. http://semanticsarchive.net/Archive/ jA3N2IwN/fintel-1994-thesis.pdf.

von Fintel, Kai. 2004. Would you believe it? The king of france is back! Presuppositions and truth-value intuitions. In Anne Bezuidenhout \& Marga Reimer (eds.), Descriptions and beyond: An interdisciplinary collection of essays on definite and indefinite descriptions and other related phenomena, 315-341. Oxford University Press.

Fodor, Janet D. 1979. In defense of the truth-value gap. In Chung-Kyu Oh \& David Dinneen (eds.), Presupposition (Syntax and Semantics 11), 199-224. New York: Academic Press. 
Foley, William \& Robert Van Valin. 1984. Functional syntax and universal grammar. Cambridge University Press.

Fox, Danny. 2012. Trivalence, local accommodation, and presupposition strengthening. HUJI and MIT.

Francez, Itamar. 2007. Existential propositions. Stanford, CA: Stanford University PhD thesis.

Frege, Gottlob. 1892. Über Sinn und Bedeutung. Zeitschrift für Philosophie und philosophische Kritik C. English Translation: On Sense and Meaning, in McGuinness, Brian (ed.), Frege: Collected works, Oxford: Basil Blackwell, 25-50.

Gazdar, Gerald. 1979. Implicature, presupposition and logical form. New York, NY: Academic Press.

Geurts, Bart. 1998. Mechanisms of denial. Language 74(2). 274-307. http: //www.jstor.org/stable/417868.

Geurts, Bart. 2007. Existential import. In Ileana Comorovski \& Klaus von Heusinger (eds.), Existence: Syntax and semantics, 253-271. Dordrecht: Springer.

Givón, Talmy. 1983. An introduction. In Talmy Givón (ed.), Topic continuity in discourse: A quantitative cross-language study, 1-41. Amsterdam/Philadelphia: John Benjamins.

Gundel, Jeanette K. 1974. The role of topic and comment in linguistic theory. Published by Garland, 1989. Austin, TX: University of Texas at Austin PhD thesis.

Gundel, Jeanette K. 1977. Role of topic and comment in linguistic theory. Bloomington, IN: Indiana University Linguistics Club.

Gundel, Jeanette K. 1985. 'Shared knowledge' and topicality. Journal of Pragmatics 9(1). 83-107. http://dx.doi.org/10.1016/o378-2166(85)90049-9.

Gundel, Jeanette K. \& Thorstein Fretheim. 2004. Topic and focus. In Laurence Horn \& Gregory Ward (eds.), The handbook of pragmatic theory, 174-196. Oxford: Blackwell.

Hajičová, Eva. 1984. Presupposition and allegation revisited. Journal of Pragmatics 8(2). 155-167. http://dx.doi.org/10.1016/0378-2166(84)90046-8.

Halliday, Michael A. K. 1967. Notes on transitivity and theme in English: Part 2. Journal of Linguistics 3(2). 199-244. http://dx.doi.org/10.1017/ Soo22226700016613.

Heim, Irene. 1983. On the projection problem for presuppositions. West Coast Conference on Formal Linguistics (WCCFL) 2. 114-125. 
Experimenting with the king of France

Horn, Larry. 1989. A natural history of negation. Chicago, IL: University of Chicago Press.

Horn, Laurence R. 1986. Presupposition, theme and variations. Chicago Linguistics Society (CLS) 22. 168-192.

Karttunen, Lauri \& Stanley Peters. 1979. Conventional implicatures in Montague Grammar. In Chung-Kyu Oh \& David Dinneen (eds.), Presupposition (Syntax and Semantics 11), 1-56. New York: Academic Press.

Kuno, Susumu. 1972. A case study from Japanese and English. Linguistic Inquiry 3(3). 269-320. http://www.jstor.org/stable/4177715.

Lambrecht, Knud. 1994. A theory of topic, focus and the mental representations of discourse referents. Cambridge University Press.

Langton, Rae \& David Lewis. 1998. Defining 'intrinsic'. Philosophy and Phenomenological Research 58(2). 333-345. http://dx.doi.org/10.2307/ 2653512.

Lasersohn, Peter. 1993. Existence presuppositions and background knowledge. Journal of Semantics (2). 113-122. http://dx.doi.org/10.1093/jos/10. 2.113 .

Lewis, David. 1986. On the plurality of worlds. Oxford: Blackwell.

Lewis, David. 1988. Statements partly about observation. Philosophical Papers 17(1). 1-31. http://dx.doi.org/10.1080/05568648809506282.

Neale, Stephen. 1990. Descriptions. Cambridge, MA: MIT Press.

Partee, Barbara H. \& Vladimir Borschev. 2004. The semantics of Russian genitive of negation: The nature and role of perspectival structure. Semantics and Linguistic Theory (SALT) 14. 212-234.

Percus, Orin. 1997. Prying open the cleft. North East Linguistic Society (NELS) 27. 337-351.

Percus, Orin. 1998. Presupposition denial and the origin of antecedents. In Uli Sauerland \& Orin Percus (eds.), The interpretive tract: Working papers in syntax and semantics. Department of Linguistics, Massachusetts Institute of Technology.

Prince, Ellen. 1997. On the limits of syntax, with reference to left-dislocation and topicalization. In Peter W. Culicover \& Louise McNally (eds.), The limits of syntax (Syntax and Semantics 29), 281-302. Academic Press.

Putnam, Hilary. 1958. Formalization of the concept about. Philosophy of Science 25(2). 125-130. http://dx.doi.org/10.1086/287584.

Reinhart, Tanya. 1981. An analysis of sentence topics. Philosophica (1). 53-94.

Reinhart, Tanya. 2006. Optimal and costly computations (Linguistic Inquiry monographs 45). Cambridge, MA: MIT Press. 
Roberts, Craige. 2003. Uniqueness in definite noun phrases. Linguistics and Philosophy 26(3). 287-350. http://dx.doi.org/10.1023/A:1024157132393.

Roberts, Craige. 2011. Topics. In Claudia Maienborn, Klaus von Heusinger \& Paul Portner (eds.), Semantics: An international handbook of natural language meaning, vol. 2, 1908-1934. Berlin/Boston. http://dx.doi.org/10. 1515/9783110255072.1908.

Russell, Bertrand. 1905. On denoting. Mind (4). 479-493. http://dx.doi.org/ 10.1093/mind/XIV.4.494.

Russell, Bertrand. 1957. Mr Strawson on referring. Mind 66(263). 385-389. http://dx.doi.org/10.1093/mind/LXVI.263.385.

Ryle, Gilbert. 1933. About. Analysis (1). 10-12. http://dx.doi.org/10.1093/ analys/1.1.10.

Schlenker, Philippe. 2008. A pragmatic theory of presupposition. Theoretical Linguistics 34(3). 157-212. http://dx.doi.org/10.1515/THLI.2008.013.

Schlenker, Philippe. 2009. Local contexts. Semantics and Pragmatics 2(3). 1-78. http://dx.doi.org/10.3765/sp.2.3.

Schoubye, Anders. 2009. Descriptions, truth-value intuitions, and questions. Linguistics and Philosophy 32(6). 583-617. http://dx.doi.org/10.1007/ s10988-010-9069-y.

Simons, Mandy. 2001. On the conversational basis of some presuppositions. Semantics and Linguistic Theory (SALT) 11. 431-448.

Soames, Scott. 1976. A critical examination of Frege's theory of presupposition and contemporary alternatives. Cambridge, MA: Massachusetts Institute of Technology PhD thesis. http://dx.doi.org/1721.1/38231.

Stalnaker, Robert C. 1974. Pragmatic presuppositions. In Milton Munitz \& Peter Unger (eds.), Semantics and philosophy: Essays. New York University Press.

Stalnaker, Robert C. 1978. Assertion. In Peter Cole (ed.), Syntax and Semantics 9, 315-332. New York: Academic Press.

Strawson, Peter F. 1950. On referring. Mind 59(235). 320-344. http://dx.doi. org/10.1093/mind/LIX.235.320.

Strawson, Peter F. 1964. Identifying reference and truth-values. Theoria 30(2). 96-118. http://dx.doi.org/10.1111/j.1755-2567.1964.tboo404.x.

Szabó, Zoltán Gendler. 200o. Descriptions and uniqueness. Philosophical Studies 101(1). 29-57. http://dx.doi.org/10.1023/A:1026437211756.

Vallentyne, Peter. 1997. Intrinsic properties defined. Philosophical Studies 88(2). 209-219. http://dx.doi.org/10.1023/A:1004250930900. 
Experimenting with the king of France

Visser, Albert. 1984. Four valued semantics and the liar. Journal of Philosophical Logic 13(2). 181-212. http://dx.doi.org/10.1007/BFoo453021.

Yablo, Stephen. 1999. Intrinsicness. Philosophical Topics 26(1-2). 479-505. http://dx.doi.org/10.5840/philtopics1999261/234.

Yablo, Stephen. 2006. Non-catastrophic presupposition failure. In Judith J. Thomson \& Alex Byrne (eds.), Content and modality: Themes from the philosophy of Robert C. Stalnaker, 164-190. Oxford University Press.

Zubizarreta, Maria L. 1998. Prosody, focus and word order. Cambridge, MA: MIT Press.

Márta Abrusán

IRIT, Université Paul Sabatier 118 Route de Narbonne

31062 Toulouse CEDEX 9

France

marta.abrusan@gmail.com
Kriszta Szendrői

UCL Linguistics, Division of Psychology and Language Sciences, Chandler House

2 Wakefield Street

London $\mathrm{WC}_{1 \mathrm{~N}} \mathrm{PPF}$, UK

k.szendroi@ucl.ac.uk 